\title{
Bilateral round lucent iliac defects
}

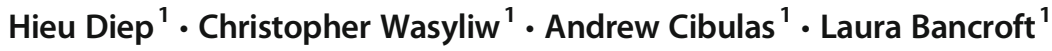

Published online: 20 July 2020

(C) ISS 2020

\section{Test Yourself: Question}

\section{Bilateral Round Lucent Iliac Defects}

Thirty-nine year old female with a history of Athrogyroposis Mutiplex Congenta, chronic bilateral hip dislocation, right hip arthroplasty and recent trauma. AP Pelvis radiograph (Fig. 1) and non-contrast CT of the Pelvis (Fig. 2) were performed to evaluate for fracture.
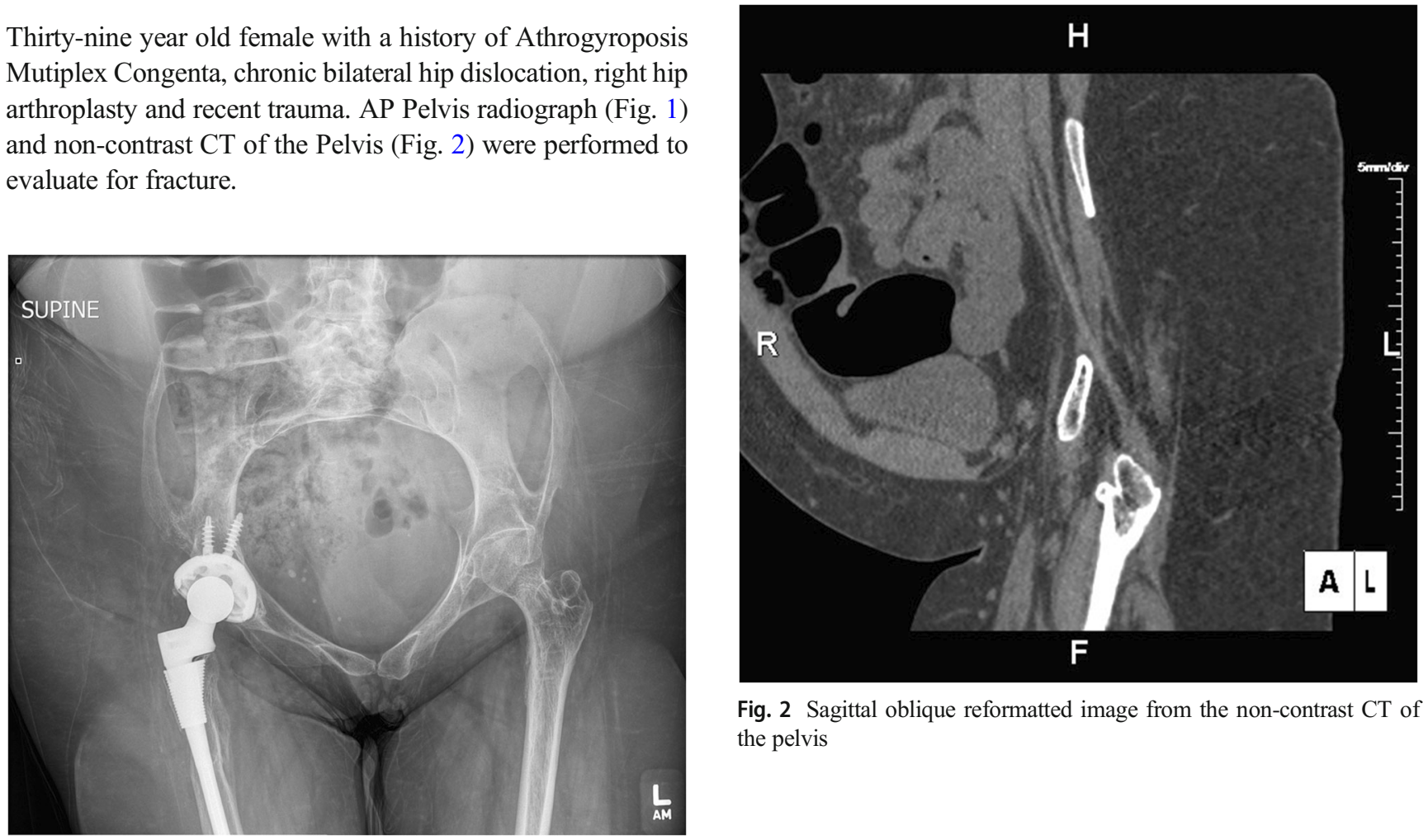

Fig. 2 Sagittal oblique reformatted image from the non-contrast CT of the pelvis

Fig. 1 AP radiograph of the pelvis

The diagnosis can be found at doi:10.1007/s00256-020-03500-1

Hieu Diep

hieu.diep.md@adventhhealth.com

1 Advent Health, 601 E Rollins St, Orlando, FL 32803, USA 